\title{
Sensitive sex determination assay applicable to bovine embryos derived from IVM and IVF
}

\author{
B. W. Kirkpatrick and R. L. Monson \\ Department of Meat and Animal Science, University of Wisconsin, Madison, WI 53706, USA
}

\begin{abstract}
A rapid, sensitive method for sex determination which uses nested, allele-specific amplification of bovine $z f x$ and $z f y$ was developed. Accuracy of the sex determination assay was verified with lymphocyte-derived DNA from 24 cattle of known gender. Reliability and sensitivity of the assay in embryonic sex determination were examined by typing duplicate bovine embryo biopsies of 2-8 cells. Sex determination was possible in 38 of 40 biopsies, and agreement between biopsy assays occurred in 17 of 18 cases. Applicability of the sex determination assay was further verified by examining gender of 12 fetuses derived from sexed embryos. Embryonic and fetal gender determinations agreed in 11 of 12 cases with the twelfth yielding an ambiguous result from fetal ultrasound examination.
\end{abstract}

\section{Introduction}

Several methods have now been reported for bovine sex determination including polymerase chain reaction (PCR) genotyping (Aasen and Medrano, 1990; Herr et al., 1990; Matthaei $e t$ al., 1990; Schröder et al., 1990; Peura et al., 1991) and detection of gender-specific antigen (Wachtel, 1984). The goal of the current study was to develop an alternative method for sex determination which would theoretically offer improved sensitivity and specificity. Both sensitivity and specificity of PCR amplification is enhanced by performing sequential PCR reactions with primer pairs in the second, or nested, PCR reaction located internally to the initial pair. Products from the first PCR reaction are greatly enriched for the targeted sequence. When the initial product is used as a template for a further, nested PCR reaction, the final product is highly specific. Nested PCR is especially useful when attempting amplification from minute amounts of template DNA, such as the quantities found in individual gametes or blastomeres. Amplification in these cases is greatly complicated by dramatic changes in DNA template concentrations relative to the concentrations of primers and reagents (Ruano et al., 1989).

An additional means of enhancing amplification specificity is the intentional location of PCR primers to include alleledistinguishing bases at their $3^{\prime}$ termini. By positioning primers in this manner, a perfect complementary pairing is formed only with one allele, and only this allele is amplified under appropriate conditions (Kwok et al., 1990; Sarkar et al., 1990). This study examined the feasibility of combining nested and allele-specific PCR to create a method of sex determination that could be reliably employed using a minimal embryo biopsy. We anticipated that embryo viability will be enhanced by minimizing the number of blastomeres removed during biopsy, which in turn necessitates the use of a highly sensitive sex determination assay.
The segment of the bovine genome exploited in this sex determination assay is a region common to both $X$ and $Y$ chromosomes, termed the pseudoautosomal region. Segments of the bovine $z f x$ and $z f y$ genes were cloned and sequenced to permit identification of $\mathrm{X}$ - and $\mathrm{Y}$-specific base sequences. Nested, allele-specific amplification of $z f x$ and $z f y$ genes was used in assessing sex of the embryo. Accuracy of the technique was examined using DNA from animals of known sex and by comparing results of embryonic and fetal sex determinations. Reliability and sensitivity of embryo sex determination were examined by assay of duplicate embryo biopsies. We show that the sex determination method described is accurate, reliable and sensitive.

\section{Materials and Methods}

\section{DNA cloning, sequence analysis and primer design}

Bovine $z f x$ and $z f y$ gene fragments were amplified using PCR primers reported by Aasen and Medrano (1990). These products were cloned in pCR1000 plasmid vector (Invitrogen, San Diego, CA) and sequenced by primer extension from both vector arms. Sequencing was performed on an automated sequencing apparatus (Applied Biosystems, Foster City, CA). Sequences were aligned using the GCG Sequence Analysis Software package (Devereux et al., 1984).

Nested PCR primers (Table I) were designed to produce $z f x$ - or $z f y$-specific products. Primer locations (Table 2) were chosen to provide a difference between $z f x$ and $z f y$ sequences. Additional mismatches were incorporated as necessary to ensure allele-specific amplification. In addition, primer locations were chosen to minimize overlap between amplified regions and to yield products that would be readily distinguishable by their size upon agarose gel electrophoresis (Fig. 1). 
Table 1. Primer sequences used in the sex determination assay

\begin{tabular}{lll}
\hline Primer & \multicolumn{1}{c}{ Derivation } & \multicolumn{1}{c}{ Sequence } \\
\hline 1. $5^{\prime}$, combined $z f x, z f y$ & Aasen and Medrano (1990) & ATAATCACATGGAGAGCCACAAGCT \\
2. $3^{\prime}$, combined $z f x, z f y$ & Aasen and Medrano (1990) & GCACTTCTTTGGTATCTGAGAAAGT \\
3. $5^{\prime} z f x$, allele-specific & Sequence data this study & GACAGCTGAACAAGTGTTACTG \\
4. $5^{\prime} z f y$, allele-specific & Sequence data this study & GAAGGCCTTCGAATGTGATAAC \\
5. 3'zfx, allele-specific & Sequence data this study & AATGTCACACTTGAATCGCATC \\
6. $3^{\prime} z f y$, allele-specific & Sequence data this study & CTGACAAAAGGTGGCGATTTCA \\
\hline
\end{tabular}

Table 2. $Z f x$ and $z f y$ sequences and location of allele-specific primers $^{a}$

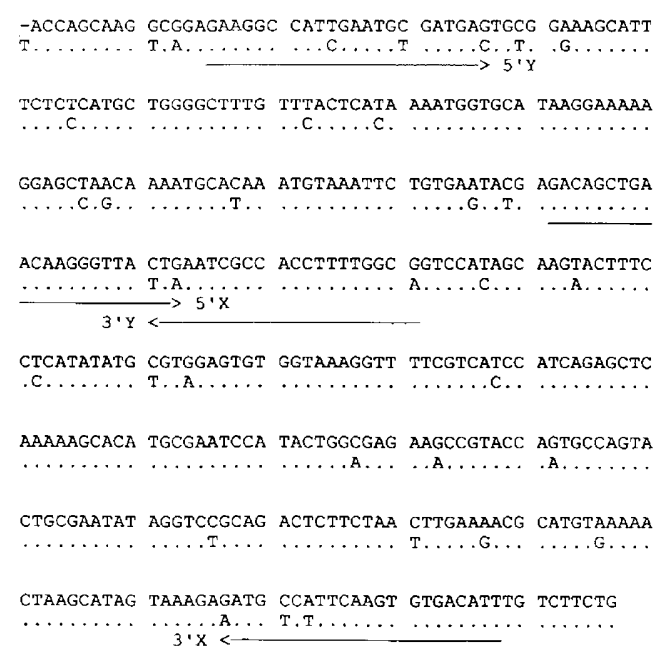

${ }^{2}$ Upper sequence is $z f x$. Corresponding bases that are identical in $z f y$ are denoted by dots, otherwise the substituted bases are denoted.

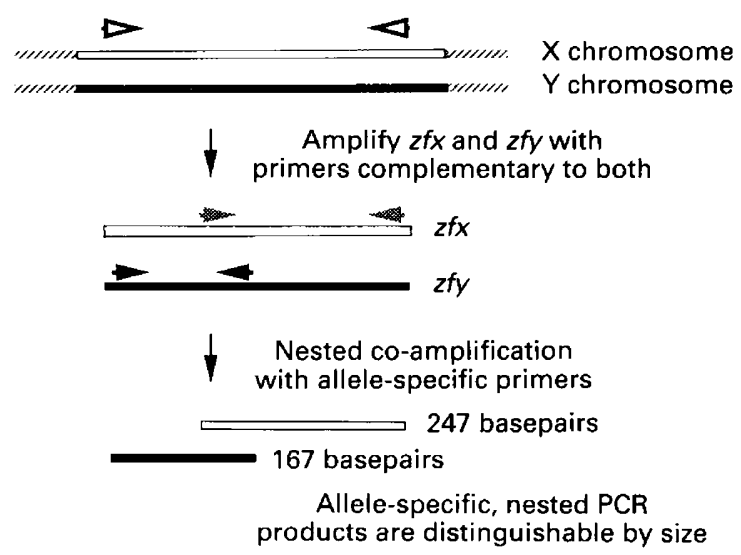

Fig. 1. Location of primers used in sex determination assay. Striped arrows denote primers $I$ and 2 of Table 1 . The open and solid lines denote segments of the pseudoautosomal regions of the $X$ and $Y$ chromosomes containing the $z f x$ and $z f y$ genes, respectively. Open arrows denote PCR primers 1 and 2 and the solid arrows denote primers $3-6$. The resultant nested PCR products were analysed by agarose gel electrophoresis.

\section{$P C R$ amplification of $\mathrm{zfx}$ - and $\mathrm{zfy}$-specific segments}

Primary PCR was performed with 30 triphasic cycles of denaturation at $95^{\circ} \mathrm{C}$ for $60 \mathrm{~s}$, annealing at $55^{\circ} \mathrm{C}$ for $45 \mathrm{~s}$ and extension at $72^{\circ} \mathrm{C}$ for $60 \mathrm{~s}$. The second, nested PCR reaction was performed in two stages with differing annealing temperatures. The first five PCR cycles were performed as previously described except for a reduction in annealing temperatures to $52^{\circ} \mathrm{C}$. The remaining $25 \mathrm{PCR}$ cycles were performed with an annealing temperature of $60^{\circ} \mathrm{C}$. Annealing temperature was reduced initially to allow for the slight mismatch occurring between the PCR primers and the intended genomic complements. Annealing temperature was raised for the remaining 25 cycles to reduce further the chance of undesired template amplification (e.g. $z f x$ amplification by $z f y$-specific primers). Zfx- and zfy-specific nested PCR products were co-amplified by including both pairs of allele-specific primers in the same PCR reaction.

PCR reactions were performed in $25 \mu \mathrm{l}$ volumes with 0.6 units of Taq polymerase per reaction (Perkin-Elmer, Branchburg, NJ), with the exception of the initial PCR reaction for embryo biopsies (described in the following paragraph). Reactions included $25 \mathrm{ng}$ genomic DNA, $1 \mu \mathrm{l}$ primary PCR product or 2-8 blastomeres as template DNA, $0.5 \mu \mathrm{mol} 1^{-1}$ each primer, $1.5 \mathrm{mmol} \mathrm{MgCl}_{2} \mathrm{I}^{-1}, 50 \mathrm{mmol} \mathrm{KCl} 1^{-1}, 0.001 \%$ gelatin (G2500: Sigma, St Louis, MO) and $200 \mu \mathrm{mol}$ each dNTP ${ }^{-1}$ (Boehringer Mannheim Biochemicals, Indianapolis, IN). Reactions were carried out in Coy Model 50 or 60 thermal cyclers (Coy Manufacturing, Ann Arbor, MI).

Primary PCR of embryo biopsies differed slightly. Before assay, embryo biopsies in $5 \mu \mathrm{l}$ of splitting media (Tyrode lactate Hepes with 0.25 mol sucrose $l^{-1}$ ) were immediately transferred to $0.5 \mathrm{ml}$ microfuge tubes containing $20 \mu \mathrm{l}$ sterile water. These were held at $-20^{\circ} \mathrm{C}$ until the time of assay. At the time of assay biopsy tubes were removed from the freezer and placed directly in boiling water for $12-15 \mathrm{~min}$. After boiling, tubes were placed on the benchtop and allowed to cool to room temperature for approximately $10 \mathrm{~min}$. Tubes were then placed on ice and $25 \mu \mathrm{l}$ of a $2 \times$ PCR master mix was added to each. Taq polymerase concentration was increased to 4 units per $50 \mu \mathrm{l}$ reaction for initial PCR amplification from embryo biopsies.

PCR products were size fractionated on $2 \%$ agarose gels ( $1 \%$ SeaKem, $1 \%$ NuSieve, FMC Bioproducts, Rockland, ME) run at a constant 150 volts $\left(7 \mathrm{~V} \mathrm{~cm}^{-1}\right)$ for $3 \mathrm{~h}$. DNA was visualized under UV light following ethidium bromide staining, and results were recorded on Polaroid type 55 film. From 8 to $20 \mu \mathrm{l}$ of PCR product was loaded depending on the DNA template (lymphocyte versus embryo biopsy). 
Four experiments were performed to assess the accuracy, specificity and sensitivity of the sex determination assay.

\section{Experiment 1: verification of accuracy of assay}

Accuracy of the assay was tested by performing the assay on genomic DNA derived from 24 cattle of known gender (12 males and 12 females). These 24 animals were selected randomly from a genetically diverse population that contained animals of 12 different cattle breeds (Gregory et al., 1990). Semen or blood was used as a source of DNA, and DNA was isolated by standard methods (Strauss, 1990).

\section{Experiment 2: species specificity of sex determination assay}

The potential for contaminating DNA to bias assay results was examined by performing the assay on samples of human DNA and ovine serum albumin (OSA), a constituent of one of the embryo wash media used. The sex determination assay was applied to ten human male and ten human female DNA samples, and to OSA with concentrations ranging from 0.05 to $0.3 \%$ of the PCR reaction corresponding to media concentrations of $0.1-0.6 \%$. In each case, the sex determination assay was simultaneously applied to male and female bovine DNA samples as a positive control.

\section{Experiment 3: applicability of the sex determination assay to embryo biopsies}

Reliability and accuracy of the sex determination assay when applied to embryo biopsies were evaluated by comparing results from assays of duplicated biopsies. Embryonic samples were derived from in vitro matured and fertilized (IVM, IVF) oocytes. Oocytes were collected from ovaries from an abattoir, and in vitro maturation and fertilization were performed according to Sirard et al. (1988). The resulting zygotes were cultured to blastocyst stage in CR-I amino acids (Rosenkrans and First, 1991). Two to ten cells were removed from compacted morulae (day 5-day 6), early-mid blastocyst (day 6-day 7) or expanding blastocysts (day 7-day 8) bovine embryos. For biopsy, embryos were held in place using a fire-polished holding pipette. Suction was applied to the opening by use of a joystick-type micromanipulator (de Fronbrune, St Louis, MO), holding the embryo securely while a slit was made in the zona pellucida with a finely drawn glass pipette. An aspiration pipette, fire polished to an outside diameter of $50-60 \mu \mathrm{m}$ was inserted into the slit and blastomeres were removed via suction. Blastomeres were left in the media drop while the remaining embryo was returned to culture. Embryo biopsies were completely free of zona pellucida fragments which may contain maternal cumulus cells or adherent spermatozoa from the IVF procedure. Embryos were washed three times in sterile media (Bavister et al., 1983) containing $0.1-0.3 \%$ OSA as a replacement for BSA. Embryo washing is required to remove bovinederived products (fetal bovine serum, BSA, and fatty acid free $B S A)$ used in the preceding embryo culture. Each of these is a potential source of contaminating bovine DNA when using IVM-IVF derived embryos. A total of 20 embryos was biopsied and assayed. Results were analysed by Chi-square test. (a)

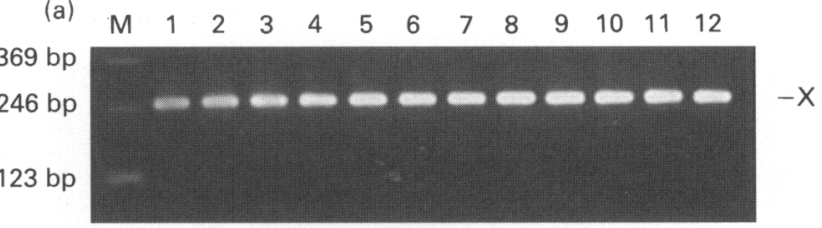

(b) $M \quad \begin{array}{llllllllllll}M & 2 & 3 & 4 & 5 & 6 & 7 & 8 & 9 & 10 & 11 & 12\end{array}$

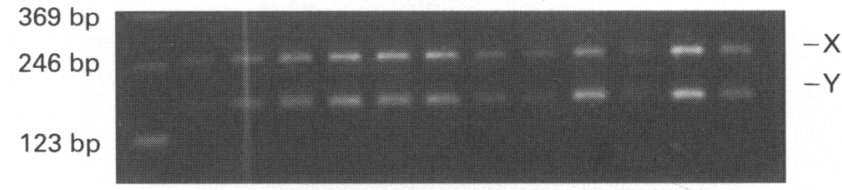

Fig. 2. (a) Sex determination assay for 12 bovine female DNA samples. Approximately $25 \mathrm{ng}$ of genomic DNA was used for template in the initial PCR reaction. All samples display a distinct $X$-specific band. (b) Sex determination assay for 12 known bovine male DNA samples. Approximately $25 \mathrm{ng}$ of genomic DNA was used for template in the initial PCR reaction. All samples display both $X$-specific and $Y$-specific bands. The lane labelled ' $\mathrm{M}$ ' contains a molecular weight standard. Size of standard bands is shown to the left in basepairs (bp).

\section{Experiment 4: verification of fetal sex determination}

Further verification of the accuracy of the assay was attained by comparing results of the sex determination assay applied to embryo biopsies with results of a fetal gender assay of the same embryos after transfer to recipient dams. A total of 18 embryos was biopsied, assayed and transferred. After biopsy, embryos were returned to the culture media drops in which they were previously cultured. Those developing to the blastocyst stage were transferred non-surgically to recipients. Fetal sex determination was performed with ultrasound at about day 60 of gestation (Curran et al., 1989, 1992). Correspondence between embryonic and fetal sex determinations was assessed by Chi-square test.

\section{Results}

Approximately $400 \mathrm{bp}$ of a corresponding segment of the $z f x$ and $z f y$ genes were successfully cloned and sequenced. Sequence analysis identified base substitutions at 34 of 396 positions (Table 2).

\section{Experiment 1}

The sex determination assay gave correct and unambiguous results for each of the 24 cattle of known gender (Fig. 2).

\section{Experiment 2}

Application of the sex determination assay to human genomic DNA resulted in a $z f x$-specific band for eight of ten male samples and all ten female samples. A zfy-specific band was not observed for any human sample. A pair of bovine male and female DNA samples was also analysed as a positive control. The bovine female samples yielded only the $z f x$-specific band, 
(a) $\begin{array}{lllllllllllll}M & 1 & 2 & 3 & 4 & 5 & 6 & 7 & 8 & 9 & 10 & B & B\end{array}$

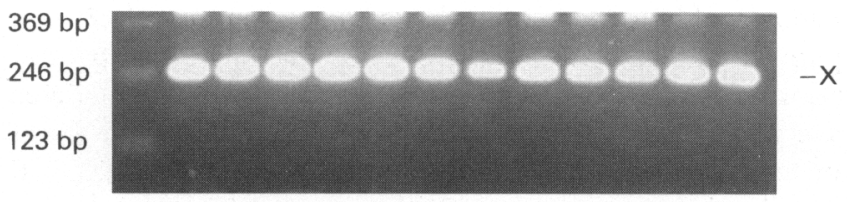

(b)

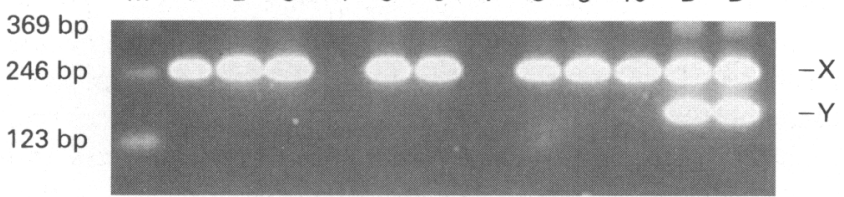

Fig. 3. Sex determination assay using human or bovine DNA (lanes denoted by B). Approximately $25 \mathrm{ng}$ of genomic DNA was used for template in the initial PCR reaction. (a) Sex determination assay for ten human female and two bovine female DNA samples. All samples display a distinct $X$-specific band. (b) Sex determination assay for 10 human male DNA samples and two bovine male DNA samples. All human samples display only the $X$-specific band while the bovine samples exhibit both $\mathrm{X}$ - and $\mathrm{Y}$-specific bands. The lane labelled ' $\mathrm{M}$ ' contains a molecular weight standard. Size of standard bands is shown to the left in basepairs (bp).

Table 3. Results from duplicate bovine embryo biopsies

\begin{tabular}{|c|c|c|c|c|}
\hline \multirow[b]{2}{*}{ Embryo } & \multicolumn{2}{|c|}{ Biopsy A } & \multicolumn{2}{|c|}{ Biopsy B } \\
\hline & Sex ${ }^{a}$ & $\begin{array}{c}\text { Number of } \\
\text { cells }^{b}\end{array}$ & Sex ${ }^{a}$ & $\begin{array}{c}\text { Number of } \\
\text { cells }^{b}\end{array}$ \\
\hline 1 & $\mathrm{M}$ & 8 & $M$ & 6 \\
\hline 2 & $\mathrm{M}$ & 4 & M & 4 \\
\hline 3 & $\mathrm{M}$ & 4 & $\mathrm{M}$ & 4 \\
\hline 4 & $\mathrm{~F}$ & 4 & NA & $?$ \\
\hline 5 & NA & $?$ & $\mathrm{~F}$ & 6 \\
\hline 6 & M & 4 & M & 4 \\
\hline 7 & M & 4 & $M$ & 4 \\
\hline 8 & $\mathrm{~F}$ & 4 & $\mathrm{~F}$ & 4 \\
\hline 9 & $\mathrm{~F}$ & 3 & $\mathrm{~F}$ & 3 \\
\hline 10 & $\mathrm{~F}$ & 3 & $\mathrm{~F}$ & 3 \\
\hline 11 & $\mathrm{~F}$ & 6 & $\mathrm{M}$ & 6 \\
\hline 12 & $\mathrm{~F}$ & 5 & $\mathrm{~F}$ & 4 \\
\hline 13 & $\mathrm{~F}$ & 6 & $\mathrm{~F}$ & 4 \\
\hline 14 & $M$ & 4 & $\mathrm{M}$ & 4 \\
\hline 15 & M & 4 & M & 4 \\
\hline 16 & $M$ & 4 & $\mathrm{M}$ & 4 \\
\hline 17 & $M$ & 4 & $\mathrm{M}$ & 4 \\
\hline 18 & $\mathrm{M}$ & 4 & $\mathrm{M}$ & 4 \\
\hline 19 & $M$ & 4 & $\mathrm{M}$ & 4 \\
\hline 20 & $M$ & 4 & $\mathrm{M}$ & 4 \\
\hline
\end{tabular}

${ }^{2} \mathrm{M}$ : male; F: female; and NA: not available owing to absence of PCR product. ${ }^{b}$ Estimate of number of cells transferred during biopsy. Samples with question marks are cases where the capillary tube containing the biopsy broke while loading the sample.
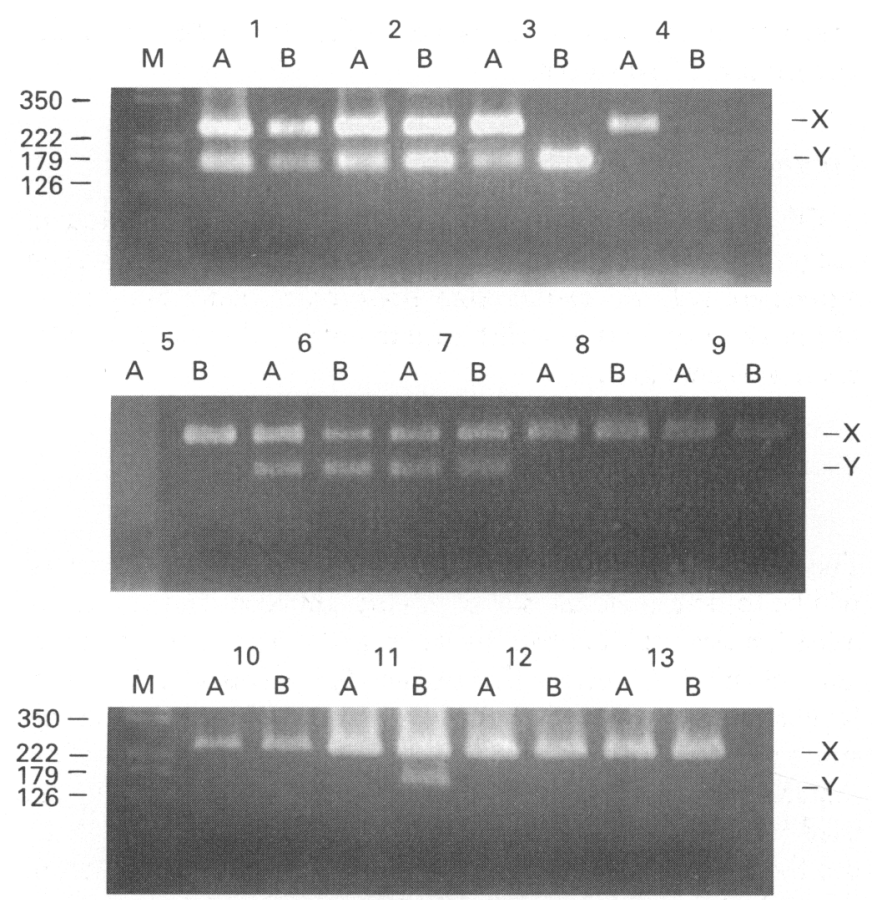

Fig. 4. Sex determination from bovine embryo biopsies. Thirteen of the 20 duplicate biopsy results are shown. Samples with numbers in common used biopsies from the same embryo. Samples $4 \mathrm{~B}$ and $5 \mathrm{~A}$ display no PCR products; assay failure in both cases may be the result of breakage of capillary transfer pipettes during transfer of the biopsies. Samples 11A and 11B exhibit the only discrepancy observed between duplicate biopsies and assays. The reason for the discrepancy is unknown. The lane labelled ' $\mathrm{M}$ ' contains a molecular weight standard. Size of standard bands is shown to the left in basepairs (bp).

and the bovine male samples yielded both $z f x$ - and $z f y$-specific bands as expected (Fig. 3).

OSA was also examined as a potential source of contaminating DNA for the sex determination assay. A $z f x$-specific band could be amplified from OSA, but consistent amplification was achieved only at high concentrations ( $0.6 \%$ in media). Consequently, OSA concentrations were kept at or below $0.3 \%$ in all subsequent assays. No evidence of a $z f y$-specific band was observed at any concentration of OSA.

\section{Experiment 3}

Sex determination was performed for a total of 40 biopsies (Table 3) from IVM- and IVF-derived bovine embryos. The sex determination assay yielded a result for 38 of 40 biopsies. The two cases where no PCR product was observed (Fig. 4) are probably attributable to loss of the sample during transfer; in both cases the capillary pipettes used to transfer the biopsy broke during transfer. Results of the sex determination assay were in agreement for 17 of the 18 duplicate biopsies in which both biopsies yielded a result. The basis for the disagreement between one pair of duplicate biopsies is unknown. These results are a significant departure $(P<0.001)$ from the expectation of half of the duplicate biopsies in agreement and half in disagreement under a null hypothesis of equally likely but random assay outcomes. The frequencies of male and female 
embryos in this sample does not differ $(P>0.05)$ from the expectation of $50 \%$ each.

\section{Experiment 4}

Of the 18 embryos sexed and transferred, 12 resulted in pregnancies. Fetal gender determination at about day 60 was in agreement with the results from embryonic gender assay in II of the 12 cases. In the twelfth case the result of the fetal gender assay was ambiguous.

\section{Discussion}

The primary application of a bovine sex determination assay will be to determine the sex of bovine embryos. The sex determination assay should be capable of functioning with a minimal amount of DNA, such as that obtained in a biopsy of 2-4 cells, to ensure maximal embryo viability in applications requiring subsequent embryo transfer. Thus, successful sex determination requires that the assay has extreme sensitivity. Nested PCR was used to increase the sensitivity of the assay. Initial attempts to use the protocol of Aasen and Medrano (1990) for bovine sex determination failed in our hands due to the inability to specifically amplify a region of the $z f x$ and $z f y$ genes from embryo biopsies. When using PCR with minute quantities of template DNA, PCR product specificity is often greatly reduced (Ruano et al., 1989). The method described here uses an initial PCR reaction to amplify the $z f x$ and $z f y$ regions, presumably along with additional non- $z f x$ and $-z f y$ segments of the genome. Although the initial PCR product is not specific enough for sex determination, the amplified DNA is enriched for the $z f x$ and $z f y$ sequences relative to the original genomic DNA. The second, nested PCR reaction then specifically amplifies segments corresponding to only the $z f x$ or $z f y$ genes. Nested PCR enhances the sensitivity and specificity of the assay, and has been applied in sex determination of mouse preimplantation embryos (Kunieda et al., 1992).

PCR primers used for the nested PCR reaction were designed to amplify non-overlapping segments of either the $z f x$ or $z f y$ genes. This approach was chosen to reduce the possibility of a $z f x$ - and $z f y$-specific primer combining to amplify a segment of either the $z f x$ or $z f y$ gene. No evidence of nonspecific nested amplification has been observed to date.

Primer locations were also chosen to yield product sizes that were sufficiently different to be readily distinguishable by simple agarose gel electrophoresis and ethidium bromide staining. As the PCR products can be directly distinguished by simple gel electrophoresis, there is no need for additional steps in the sex determination assay, such as restriction digest, to distinguish between $z f x$ - and $z f y$-specific products. Elimination of restriction digest reduces assay cost and time, the latter being critical for maximal embryo viability. Assay time can be reduced from the $9 \mathrm{~h}$ required for the protocol described here. In subsequent studies electrophoresis time has been reduced to as little as $45 \mathrm{~min}$ at the same voltage with adequate band separation. Consequently, the sex determination assay can be performed in $6-7 \mathrm{~h}$ as described with further improvement possible by PCR protocol modification (reduced cycle number in the primary PCR reaction and reduced incubation time).
Design of allele-specific primers was complicated by the minority of transversion type base substitutions (pyrimidine for purine and vice versa). Transversion mutations create purinepurine or pyrimidine-pyrimidine mismatches at the mutated site in otherwise complementary DNA strands. These types of mismatch are most effective in reducing nonspecific PCR amplification. Kwok et al. (1990) reported a I00-fold reduction in PCR product yield from single adenine-guanine, guanineadenine or cytosine-cytosine mismatches at the $3^{\prime}$ primer terminus, and a 20 -fold reduction for a single adenine-adenine mismatch. Transition type base substitutions were effectively used for allele-specific amplification in this study by locating primer $3^{\prime}$ termini within clusters of transition mutation sites, and by strategically incorporating additional base changes within three to eight bases of the primer $3^{\prime}$ termini. The additional base substitutions intentionally incorporated in the PCR primers create a single mismatch site with the desired template which alone is insufficient to alter amplification efficiency. In the alternative case, these substitutions accentuate the degree of mismatch between the primer and undesired template and further ensure allele-specific amplification.

The position and type of added base mismatch were varied until equivalent product yields were obtained for the $z f x$ and $z f y$ bands when amplified from bovine male DNA isolated from lymphocytes. Equivalent amplification of the allelic bands is routinely attained when amplification is performed with $25 \mathrm{ng}$ of genomic DNA in a $25 \mu \mathrm{l}$ reaction, an amount of DNA that would contain several thousand copies of each allele. In contrast, a two-cell biopsy of a male embryo will contain two copies of each allele. In this case, random differences in allelic amplification in early rounds of PCR will be perpetuated by the succeeding PCR cycles. Thus the relative yields of allelic products when starting with male embryo biopsies are more variable. Equivalent allelic amplification is expected when considering results from a group of samples. Repeated departure from relatively equal amounts of $X$ - and $Y$-specific PCR products may be diagnostic of contaminating DNA from the media, technician or the biopsy itself (for example cumulus cells).

Bovine-derived media constituents have been reduced or eliminated in various phases of embryo culture to reduce the possibility of contaminating bovine DNA which might bias results of the sex determination assay. One previously described sex determination assay (Aasen and Medrano, 1990) faithfully amplifies $z f x$ and $z f y$ regions form several species. Such broad species applicability is detrimental when determining embryo sex from a biopsy of few $(\leqslant 8)$ embryonic cells. Contaminating DNA from a male technician or non-bovine media constituents could bias assay results. Our results indicate that neither human nor ovine $z f y$ genes are effectively amplified by the $z f y$-specific primers used in this study.

Contamination from the biopsy procedure is possible if the entire blastomere is not expelled intact into its holding drop before the next aspiration or if individual cells are lysed during the procedure. However, the alternative method of embryo splitting or slicing has greater potential for contamination through introduction of zona pellucida fragments and attached cumulus cells and adherent spermatozoa.

The misclassification most likely to occur from non-bovine DNA with this sex determination assay would result from amplification of human or ovine $z f x$ without amplification of 
bovine DNA. The results presented here with duplicate biopsies and other results (unpublished) with non-replicated biopsies do not indicate a departure from a 50:50 male:female sex ratio. In addition, in two cases where bovine DNA probably was absent from the PCR reaction, neither X- or Y-specific bands were observed. Thus, neither human nor ovine DNA contamination has proved problematic in our application of the sex determination assay. Should such contamination prove problematic the location of the bovine $z f x$-specific primers could easily be modified to maximize the difference between bovine and human $z f x$ as well as between bovine $z f x$ and $z f y$ genes.

The $z f x$ and $z f y$ sequences described here could also be exploited in sex determination assays by ligase chain reaction (LCR) with or without initial PCR. Like PCR, LCR can be used to increase exponentially the amount of a DNA segment corresponding to a specific genomic segment. LCR can distinguish between corresponding genomic segments that differ by only a single base, and is reported to do so with extreme fidelity (Barany, 1991). An LCR assay that focused on segments differing not only between bovine $z f x$ and $z f y$, but also between bovine $z f x$ and human $z f x$ or bovine and human $z f y$ would virtually eliminate any possibility of error from contaminating human DNA.

The sex determination assay developed in this study will be a useful adjunct to the technologies of in vitro oocyte maturation and fertilization, embryo transfer and cloning. In vitro matured and fertilized ova will represent an expanding source of embryos for transfer due to the reduced cost of attainment compared with embryos collected from superovulated and flushed recipients. A sex determination assay of this kind will also facilitate scientific studies of gender differences in embryonic and fetal gene expression and development.

The authors wish to thank B. Huff for assistance in cloning the $z f x$ and $z f y$ PCR products, K. Strawn and R. Simonis for assistance with embryo culture and sex determination assay, and D. Northey for assistance with embryo biopsies.

\section{References}

Aasen E and Medrano JF (1990) Amplification of the $z f y$ and $z f x$ genes for sex identification in humans, cattle, sheep and goats Bio/Technology 8 I $279-1281$
Barany F (1991) Genetic disease detection and DNA amplification using cloned thermostable ligase Proceedings of the National Academy of Sciences USA $\mathbf{8 8}$ 189-193

Bavister BD, Leibfried ML and Lieberman G (1983) Development of preimplantation embryos of the golden hamster in a defined culture medium Biology of Reproduction 28 235-247

Curran S (1992) Fetal sex determination in cattle and horses by ultrasonography Theriogenology 37, 17-21

Curran S, Kastelic JP and Ginther OJ (1989) Determining sex of the bovine fetus by ultrasonic assessment of the relative location of the genital tubercle Animal Reproduction Science 19, 217-227

Devereux J, Haeberli $P$ and Smithies $O$ (1984) A comprehensive set of sequence analysis programs for the VAX Nucleic Acids Research 12 387-395

Gregory KE, Echternkamp SE, Dickerson GE, Koch RM and Van Vleck LD (1990) Twinning in cattle: I. Foundation animals and genetic and environmental effects on twinning rate Joumal of Animal Science 68 1867-1876

Herr CM, Matthaei KI, Bradley MP and Reed KC (1990) Rapid, accurate sexing of livestock embryos Proceedings of the 4th World Congress on Genetics Applied to Livestock Production Vol. XVI pp 334-343 Eds WG Hill, R Thompson and JA Wooliams. Organising Committee, Edinburgh

Kunieda T, Xian M, Kobayashi E, Imamichi T, Moriwaki K and Toyoda Y (1992) Sexing of mouse preimplantation embryos by detection of $Y$ chromosomespecific sequences using polymerase chain reaction Biology of Reproduction 46 692-697

Kwok S, Kellog DE, McKinney N, Sapsic D, Goda L, Levenson C and Sninsky JJ (1990) Effects of primer-template mismatches on the polymerase chain reaction: human immunodeficiency virus type 1 model studies Nucleic Acids Research 18 999-1005

Matthaei KI, Herr CM, Bradley MP and Reed KC (1990) Analysis of the sex chromosome constitution of single bovine spermatozoa by polymerase chain reaction (PCR) Theriogenology 33285 (Abstract)

Peura T, Hyttinen J-M, Turunen M and Jänne J (1991) A reliable sex determination assay for bovine preimplantation embryos using the polymerase chain reaction Theriogenology 35 547-555

Rosenkrans CF, Jr and First NL (1991) Culture of bovine zygotes to the blastocyst stage: effects of amino acids and vitamins Theriogenology 35266 (Abstract)

Ruano G, Fenton W and Kidd KK (1989) Biphasic amplification of very dilute DNA samples via 'booster' PCR Nucleic Acids Research 175407

Sarkar G, Cassady J, Bottema CDK and Somer SS (1990) Characterization of polymerase chain reaction amplification of specific alleles Analytical Biochemistry $18664-68$

Schröder A, Miller JR, Thomsen PD, Roschlau K, Avery B, Phoulsen PH, Schmidt M and Schwerin M (1990) Animal Biotechnology 1 121-133

Sirard MA, Parrish JJ, Ware CB, Leibfried-Rutledge ML and First NL (1988) The culture of bovine oocytes to obtain developmentally competent embryos Biology of Reproduction 39 546-552

Strauss WM (1990) Preparation of genomic DNA from mammalian tissue. In Current Protocols in Molecular Biology pp 2.2.1-2.2.2 Eds FA Ausubel, R Brent, RE Kingston, DD Moore, JD Seidman, JA Smith and K Struhl. Greene Publishing and Welsey Interscience, New York

Wachtel SS (1984) H-Y antigen in the study of sex determination and control of sex ratio Theriogenology 21 18-27 